\title{
Interactive comment on "A long-term record of blended satellite and in situ sea surface temperature for climate monitoring, modeling and environmental studies" by V. Banzon et al.
}

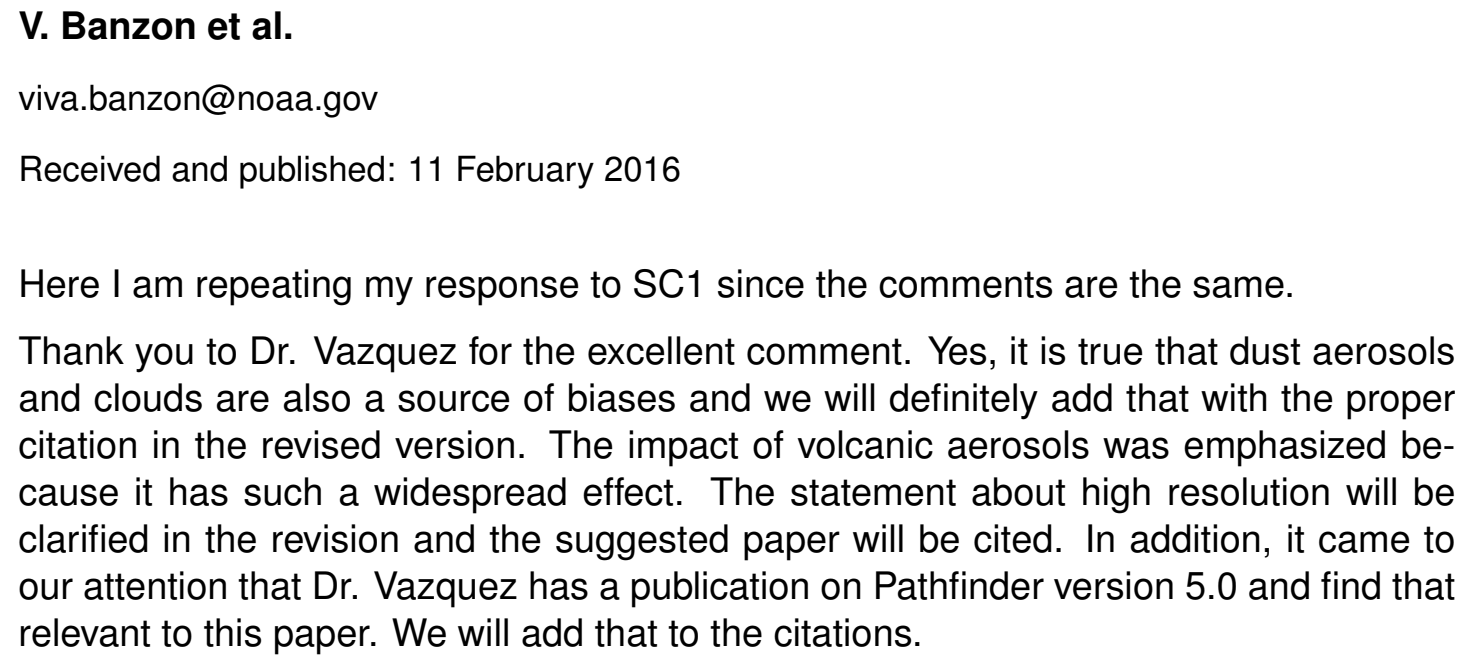
and clouds are also a source of biases and we will definitely add that with the proper citation in the revised version. The impact of volcanic aerosols was emphasized because it has such a widespread effect. The statement about high resolution will be clarified in the revision and the suggested paper will be cited. In addition, it came to our attention that Dr. Vazquez has a publication on Pathfinder version 5.0 and find that relevant to this paper. We will add that to the citations. 
Interactive comment on Earth Syst. Sci. Data Discuss., doi:10.5194/essd-2015-44, 2016.

ESSDD

Interactive

comment 